\title{
PROGRESS IN THE STANDARDIZATION OF DSM TERMINOLOGY, REPORTING FORMATS, AND EVALUATION PROTOCOLS
}

by

Linda Berry

October 1994

Prepared for the

Office of Energy Efficiency and Renewable Energy

U.S. Department of Energy

Prepared by the

Oak Ridge National Laboratory

Oak Ridge, Tennessee 37831

Managed by Martin Marietta Energy Systems, Inc. for the U.S. Department of Energy

Under Contract No. DE-AC05-840R21400 
$=$ 


\section{DISCLAIMER}

This report was prepared as an account of work sponsored by an agency of the United States Government. Neither the United States Government nor any agency thereof, nor any of their employees, make any warranty, express or implied, or assumes any legal liability or responsibility for the accuracy, completeness, or usefulness of any information, apparatus, product, or process disciosed, or represents that its use would not infringe privately owned rights. Reference herein to any specific commercial product, process, or service by trade name, trademark, manufacturer, or otherwise does not necessarily constitute or imply its endorsement, recommendation, or favoring by the United States Government or any agency thereof. The views and opinions of authors expressed herein do not necessarily state or reflect those of the United States Government or any agency thereof. 


\section{DISCLAIMER}

Portions of this document may be illegible in electronic image products. Images are produced from the best available original document. 


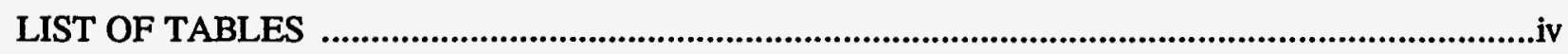

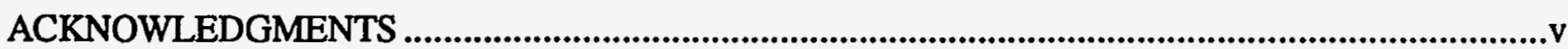

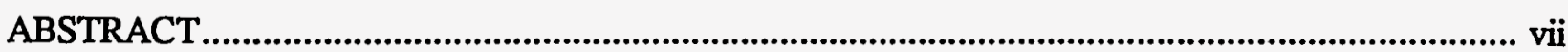

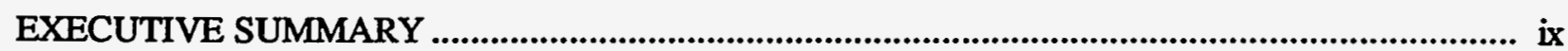

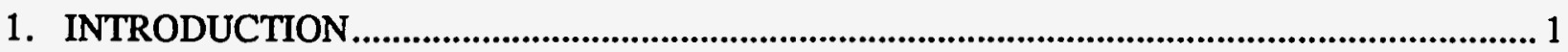

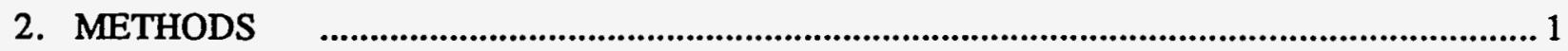

3. FINDINGS

3.1 Degree of Standardization..............................................................................................

3.1.1 Gross and net savings......................................................................................... 2

3.1.2 Free riders and free drivers..................................................................................... 3

3.1.3 Program costs ............................................................................................................ 4

3.1.4 Participation rates.................................................................................................... 5

3.1.5 Ex ante vs. ex post methods ...................................................................................... 6

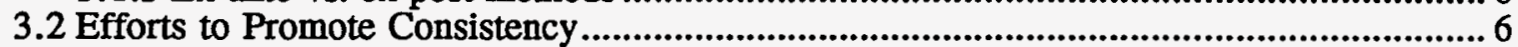

3.2.1 Current Status of Efforts to Promote Consistency.......................................................... 6

3.2.2 Evaluation Protocols .................................................................................................... 8

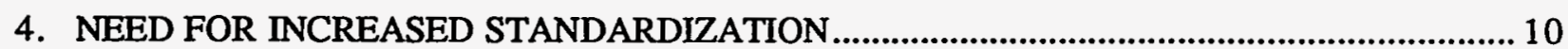

5. GOVERNMENTAL AND REGULATORY ROLES IN PROMOTING STANDARDIZATION .. 11

REFERENCES

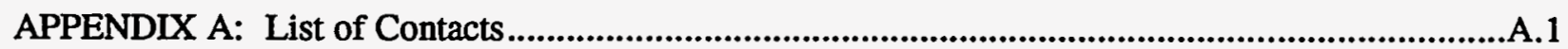

APPENDIX B: Telephone Discussion Guide .....................................................................................

APPENDIX C: List of Documents Examined ...................................................................................

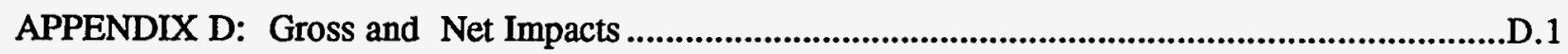

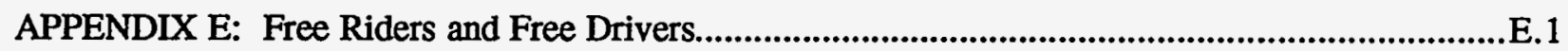

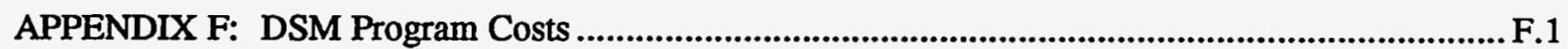

APPENDIX G: Participation........................................................................................................ 


\section{LIST OF TABLES}

Table 1. Variations in Definitions of Relationship of Gross and Net Savings ............................. 3

Table 2. Variations in Definitions of Cost Categories ........................................................... 4

Table 3. Sources of Inconsistencies in Participation Rates ....................................................... 6

Table 4. Efforts to Promote Consistency in Terminology, Data Reporting, and Evaluation

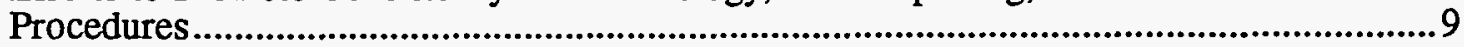




\section{ACKNOWLEDGEMENTS}

The author is grateful to the individuals listed in Appendix A for taking the time to discuss the issues addressed in this report. Without their assistance, it could not have been completed. I would also like to acknowledge the support, guidance, and insightful comments provided by Diane Pirkey of the U.S. Department of Energy. Eric Hirst and Marilyn Brown provided valuable assistance at several stages of project development and reviewed the material carefully. Dan Bell assisted with the report layout and formatting. 



\begin{abstract}
Evaluations of demand-side management programs are numerous and serve many purposes: assessing effectiveness, promoting program improvements, guiding planning processes, and determining the level of shareholder incentives. Although many program evaluations are available, it is difficult to combine or compare results because of inconsistencies in definitions, reporting formats, and evaluation methods. The increased use of explicit and standardized definitions of terms, consistent data reporting formats, and comparable methods is needed to make combining and comparing results across a range of programs, utilities, and state jurisdictional boundaries possible. Producing consistent and accurate comparisons of program experience is an important, although challenging and, therefore, underutilized, means of identifying the key elements of effective programs and of improving future programs.

In spite of the importance of arriving at standard terminology and data reporting conventions, progress is slow. The purpose of this report is to assess progress toward standardization by reviewing attempts to promote standardization and by determining the degree of consistency in various sources.

There are a number of efforts to promote standardization including regional utility efforts such as Northeast Regional DSM Data Exchange and NU-Trak in the Pacific Northwest, state regulatory commission requirements, and Lawrence Berkeley Laboratory and Oak Ridge National Laboratory databases and publications, which are national in scope. A variety of other organizations such as the Association of Demand-Side Management Professionals, the Electric Power Research Institute, the National Association of Regulatory Utility Commissioners, the Energy Information Administration, the Synergic Resources Corporation, the Environmental Protection Agency, and the National Association of Energy Service Companies have publications and/or training courses designed to promote greater standardization.

Although the number of glossaries of terms, of data reporting systems, and of evaluation protocols is growing, consensus is an elusive goal. Some glossaries make distinctions that are not found in others. Data reporting systems vary in their level of detail and in their definitions of some terms. The requirements of evaluation protocols vary.
\end{abstract}




\section{EXECUTIVE SUMMARY}

Evaluations of demand-side management programs are numerous and serve many purposes: assessing effectiveness, promoting program improvements, guiding planning processes, and determining the level of shareholder incentives. Although many program evaluations are available, it is difficult to combine or compare results because of inconsistencies in definitions, reporting formats, and evaluation methods. The increased use of explicit and standardized definitions of terms, consistent data reporting formats, and comparable methods is needed to make combining and comparing results across a range of programs, utilities, and state jurisdictional boundaries possible. Producing consistent and accurate comparisons of program experience is an important, although challenging and, therefore, underutilized, means of identifying the key elements of effective programs and of improving future programs.

In spite of the importance of arriving at standard terminology and data reporting conventions, progress is slow. The purpose of this report is to assess progress toward standardization by reviewing attempts to promote standardization and by determining the degree of consistency in various sources. Findings are summarized below.

The Northeast Regional DSM Data Exchange (NORDAX), which was one of the first major attempts to produce a consistent set of data from many utilities on program results that could be used for program design and integrated resource planning. At present, NORDAX has discontinued data collection and faces an uncertain future because its member utilities have discontinued support.

A more recent attempt to define consistent terminology and data reporting formats for utilities, commissions, and regional planners is the NU-Trak System being developed by the Northwest Power Planning Council. NU-Trak is a data collection and analysis system which was developed in a collaborative process with the Public Utility Commissions of Washington, Oregon, Idaho, and Montana, all six investor-owned utilities in these States, the Bonneville Power Administration, and the four largest public utilities in the region. The purposes of NU-Trak include those of NORDAX (improving the processes of program design and integrated resource planning) plus the goal of providing useful information to state utility regulators. The principal developer of NU-Trak said it was a concept in April 1992. Now the first "green book" is available, which contains blank forms, full instructions for the forms, a data dictionary and glossary, and a flow chart. Still under development is a second "green book" which will have two volumes: an update of the first green book and a second volume of about 500 pages which is a data dump on over 300 programs. An evaluation module for NU-Trak also is under development. It should be ready in the fall of 1994 .

At the national level, efforts to promote standard terminology and data reporting include the Oak Ridge National Laboratory publication, Electric Utility DSM Programs: Terminology and Reporting Formats, and Lawrence Berkeley Laboratory's Database of Energy-Efficiency Programs (DEEP), which

collects data that are national in scope. The objective of DEEP is to document, consistently and 
comprehensively, the measured cost and performance of utility-sponsored DSM programs across state jurisdictional boundaries. The developers of DEEP recognize that the consistent nationwide documentation of program results is extremely challenging because of the lack of standard definitions, reporting formats, and evaluation methods. Accordingly, DEEP is highly rigorous in several respects: consistent definitions of values, inclusion of customer cost contributions, extensive verification with utility staff, and the use of normalization procedures to ensure comparability. Although DEEP's rigorous procedures greatly reduce inconsistencies, a recently published DEEP report on 20 commercial lighting programs illustrates that consistent comparisons across programs are still often problematic (Eto, Vine, Shown, Sonnenblick, and Payne, 1994).

In December 1992, the Association of Demand-Side Management Professionals (ADSMP) issued a compendium of glossaries of terms and definitions used in DSM evaluation. Beginning in 1989, the Energy Information Administration has required electric utilities to provide annual reports on their DSM activities in a consistent format.

Several state regulatory commissions, including California, Massachusetts, New York, and Vermont, have adopted standardized data reporting formats for their utilities. Massachusetts has the most extensive reporting format, which was first developed in 1989 (it has been revised since then, although an effort was made to keep as much consistency as possible to allow for comparisons over time). Vermont's standard data reporting requirements started in 1992. Wisconsin is in the process of developing a standard data reporting form, but nothing is adopted yet.

Perhaps because of the 1993 California decision to adopt a detailed set of DSM evaluation protocols, concern about the issue of evaluation standards is growing. ADSMP issued a white paper on DSM program evaluation standards and guidelines in March, 1994. The National Association of Regulatory Utility Commissioners published a guide for commissioners entitled Regulating DSM Program Evaluation: Policy and Administrative Issues for Public Utility Commissions in April 1994. In most states with evaluation guidelines (of which there are about 15), the guidance is highly collaborative, developed on a case-by-case utility-specific basis, and does not involve a formal written protocol.

Three regulatory agencies adopted evaluation protocols in 1993: the California Public Utility Commission, the New Jersey Board of Regulatory Commissioners, and the U.S. Environmental Protection Agency (EPA). The EPA Conservation Verification Protocols (CVP) were developed as part of the implementation of the Acid Rain Program of the Clean Air Act Amendments of 1990, which created a new tradable commodity, the $\mathrm{SO}_{2}$ emission allowance. The verification of energy-efficiency savings from DSM programs is essential to this market approach. The CVP will probably be used mainly by public utilities, because investor owned utilities may verify savings with procedures specified by their regulatory commissions. The protocol that New Jersey adopted is almost exactly the same as the verification protocol developed by The National Association of Energy Service Companies in their publication, NAESCO Standard for Measurement of Energy Savings for Electric Utility Demand Side 
Management (DSM) Projects. The State of Indiana is currently engaged in a rulemaking which will require specific types of data reporting and benefit/cost tests. Its requirements are a "moderate approach" (less extensive than the California requirements).

Although the number of glossaries of terms, of data reporting systems, and of evaluation protocols is growing, consensus is an elusive goal. Some glossaries make distinctions that are not found in others. Data reporting systems vary in their level of detail and in their definitions of some terms. The requirements of evaluation protocols vary. 


\section{PROGRESS IN THE STANDARDIZATION OF DSM TERMINOLOGY, REPORTING FORMATS, AND EVALUATION PROTOCOLS}

\section{INTRODUCTION}

Evaluations of demand-side management programs are numerous and serve many purposes: assessing effectiveness, promoting program improvements, guiding planning processes, and determining the level of shareholder incentives. Although many program evaluations are available, it is difficult to combine or compare results because of inconsistencies in definitions, reporting formats, and evaluation methods. The increased use of explicit and standardized definitions of terms, consistent data reporting formats, and comparable methods is needed to make combining and comparing results across a range of programs, utilities, and state jurisdictional boundaries possible. Producing consistent and accurate comparisons of program experience is an important, although challenging and, therefore, underutilized, means of identifying the key elements of effective programs and of improving future programs.

In spite of the importance of arriving at standard terminology and data reporting conventions, progress has been slow. The purpose of this report is to assess the current degree of standardization in terminology, data reporting, and evaluation procedures.

\section{METHODS}

The research discussed in this report began by conducting telephone discussions with the evaluation experts and utility regulators listed in Appendix A. About half of the telephone calls were to evaluation experts who are involved with or familiar with efforts to promote standardized terminology, data reporting formats, and evaluation protocols. The rest of the calls were to utility regulatory commission staff in states where standardized data reporting formats or evaluation protocols seemed likely to have been adopted or to be under consideration. Whenever relevant documents were discussed during the interviews, I asked the respondent to mail a copy to me. The questions covered in these telephone discussions are shown in Appendix B.

A simultaneous effort was made to locate, assemble and examine DSM terminology glossaries, data reporting forms, evaluation protocols and training materials. A list of the materials assembled is shown in Appendix C. These materials were examined to determine the degree to which common terminology, data reporting formats, and evaluation practices are being promoted (and/or mandated) by state utility regulatory commissions and by other organizations [such as the Association of Demand-Side Management Professionals (ADSMP), the Electric Power Research Institute (EPRI), the National Association of Regulatory Utility Commissioners (NARUC), and the U.S. Department of Energy (DOE)]. 


\section{FINDINGS}

\subsection{Degree of Standardization}

Although the number of glossaries of terms, of data reporting systems, and of evaluation protocols is growing, standardization is an elusive goal. Some glossaries make distinctions that are not found in others and terms that are defined in some documents are not defined in others. Data reporting systems vary in their level of detail and in their definitions of terms. The requirements of evaluation protocols vary.

In general, more technical terms, such as coincident peak demand or air changes per hour, are defined consistently. Most program-related terms, such as net and gross savings, participation rates, free riders, and persistence of savings, have some areas of agreement and some areas of difference. Some terms such as cost categories are defined inconsistently. As examples of the variations in the consistency of terminology, compilations of definitions from various glossaries are presented in Appendices D (net and gross savings), E (free riders and free drivers), F (costs), and G (participation) and briefly summarized below. The topics of participation, net and gross savings, and costs were selected because they are vital to determinations of program cost effectiveness. The topic of free riders and free drivers was selected because it plays an important role in the determination of net savings.

3.1.1 Gross and net savings. In general, gross savings are unadjusted energy savings that may result from a variety of causes, while net savings are adjusted (usually only for free riders) to remove the influence of causes other than the DSM program (Appendix D). Thus, gross savings may be attributed to a variety of causes, while net savings are, in theory, attributable only to the DSM program. Possible adjustments for factors other than free ridership are mentioned in some definitions (Table 1), but not in others. The DEEP instructions have the most comprehensive list of possible adjustments including free riders, free drivers, weather ${ }^{1}$, building occupancy, building function, etc. (Appendix D). The NORDAX, NU-Trak, and DEEP definitions make temporal distinctions among incremental, annual and cumulative effects which are not given in the other definitions (Table 1). Inconsistencies among gross and net savings estimates developed in different evaluations may arise because of differences in the type and number of adjustments used to convert gross estimates to net estimates. Differences in the methods of making the adjustments also are a likely source of inconsistency.

\footnotetext{
${ }^{1}$ Weather adjustments are often made to gross savings. Of course, if gross savings were adjusted for weather, no weather adjustment is needed to convert gross to net. The other adjustments are usually made only to net savings.
} 
Table 1. Variations in Definitions of Relationship of Gross and Net Savings

\begin{tabular}{|c|c|c|}
\hline Source of befinition: & Time Dimension issspecined & Adjustraent only for Free \\
\hline Hirst and sabo: & $\mathbf{n o}^{\mathrm{a}}$ & no \\
\hline 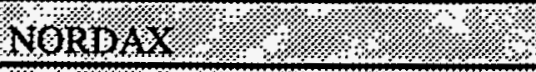 & yes & yes \\
\hline 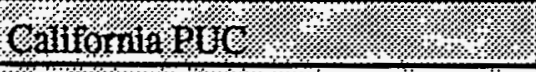 & no & no \\
\hline Wroletteres alva & no & no \\
\hline 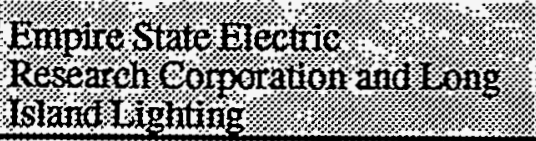 & no & yes \\
\hline 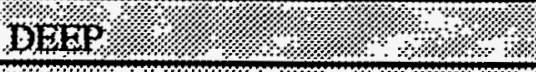 & yes & no \\
\hline 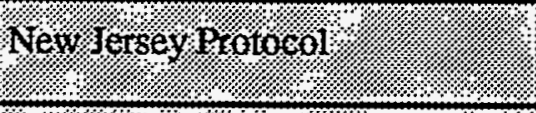 & no & $\begin{array}{l}\text { only gross savings are } \\
\text { measured/no adjustments }\end{array}$ \\
\hline 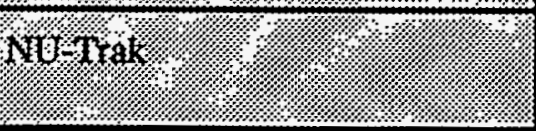 & yes & $\begin{array}{l}\text { gross/net distinction is not } \\
\text { included in the definition }\end{array}$ \\
\hline
\end{tabular}

a Hirst and Sabo (1991) do discuss temporal distinctions in the text of their report, however.

3.1.2 Free riders and free drivers. Free riders are always defined as program participants who would have undertaken program actions even in the absence of the program (Appendix E). Although the term is clear conceptually, measuring it accurately presents difficult problems. Nevertheless, there are many attempts to measure free ridership and a free ridership factor is often used to convert gross savings to net savings.

A distinction that is not contained in the glossary definitions but which is present in the text of some of the sources concerns the degree of free ridership. Hirst and Sabo (1991) discuss three different types of free riders: complete, partial, and delayed. Complete free riders are customers who would have adopted fully the utility recommendations. Partial free riders are customers who would have adopted only some of the recommendations without the program or would have purchased equipment or appliances that are more efficient than average but less efficient than those the program promotes. Delayed free riders are customers who would have adopted some or all of these recommendations, but only some time in the future. Such degrees of free ridership certainly exist, but the issue of how to measure them is unresolved.

Free drivers are people who are not formally program participants, but who reduce energy use because they are aware of the energy efficiency program or because of program-induced changes in the marketplace. There are few attempts to measure the concept of free drivers. Impacts of free drivers, and more broadly of spillover or market transformation effects, are seldom included in efforts to determine net-to-gross ratios. 
3.1.3 Program costs are usually defined and reported inconsistently. Because each utility uses its own accounting procedures, the number and types of cost categories vary markedly among utilities. Some utilities may include administrative, program planning, development, and evaluation costs as part of DSM program expenses while others do not. In addition, information on non-utility costs, to participants or trade allies, often is not collected.

Only three of the glossaries contained definitions of DSM program cost categories (Hirst and Sabo, NORDAX, and DEEP). The definitions and types of cost categories presented in these three efforts at standard reporting differ in several respects (Table 2 and Appendix F). For example, marketing costs are a separate category in Hirst and Sabo, but are part of other categories in NORDAX and DEEP. Administrative costs include marketing costs in DEEP, but are included in different cost categories, such as implementation/delivery and planning costs, in NORDAX.

All three of the glossaries with cost category definitions were developed by researchers in an effort to provide standard reporting formats that could be used to collect consistent data from a variety of programs. In practice, even when a standard set of categories, such as one of these three, is used, the collection and interpretation of information on program costs from different utilities is difficult because each utility uses its own accounting procedures. The number and types of cost categories vary much more among utilities than they do among the data collection forms developed by researchers.

Table 2. Variations in Definitions of Cost Categories

\begin{tabular}{|c|c|c|}
\hline 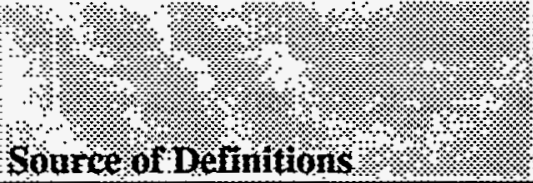 & 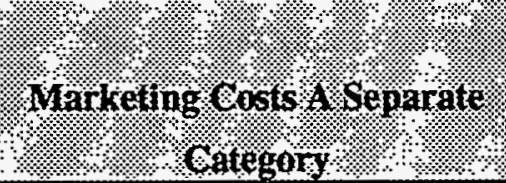 & 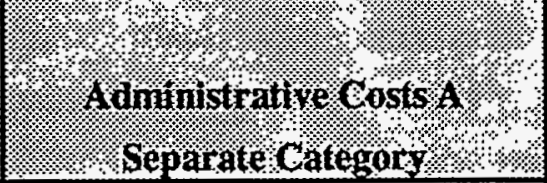 \\
\hline 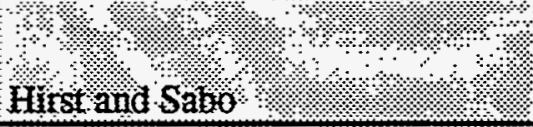 & yes & yes \\
\hline $\mathrm{NORAA}$ & no & no \\
\hline DEEP & no & yes \\
\hline NUTrak 2 - & yes & yes \\
\hline
\end{tabular}

Consider total program costs as an example of the lack of standardization in cost reporting. The range of expenses included in total program costs varies because some utilities include program planning, development, and evaluation as part of DSM expenses while others do not. In addition, some components of administrative costs often are not included in total program costs. In many cases administrative or overhead costs not specific to the program are missing although they are necessary to the operation of the program. In addition, information on non-utility costs, to participants or trade allies, often is not collected. 
3.1.4 Participation rates are the ratio (expressed as a percent) of the number of participating units to the number of units eligible for the program. A variety of types of units that are used for reporting the number of participants and the number of eligibles are shown in Table 3. The NORDAX data reporting form asks for both a participation rate based on customer units and one based on technology units. Varying definitions of participating units and eligible units (numbers of customers, account numbers, numbers of buildings, floor space, $\mathrm{kW}$ of end-use load, or specific equipment) are likely to produce different results. For example, if the eligible market is defined as owners of specific equipment rather than as the entire customer class, participation rates will be higher. In addition, participation may occur in stages. For instance, an applicant may first apply for services, then receive an audit, and then convert audit results into actual installations of equipment. Participation rates based on numbers of audits could be much higher than rates based on actual installations. Because rates may be annual or cumulative (over the program lifetime) the time period being considered is another possible source of inconsistency. Table 3 summarizes likely sources of inconsistency.

Most of the sources which define participation rates, as shown in Appendix G, do distinguish types of participating and eligible units and do specify time periods (annual and cumulative). Although the range of elements in the definitions may be consistent, inconsistencies in reported results persist because the units and the time periods used often vary and are frequently left unspecified. A recent study of 20 commercial lighting programs, for example, found that differences in the definitions of a program participant (account number, customer, and rebates paid) as well as differences in definitions of the eligible population, could have large effects on the magnitude of participation rates (Eto, Vine, Shown, Sonnenblick, and Payne, 1994).

3.1.5 Ex ante vs. ex post methods. Like definitions of DSM terminology and data reporting formats, evaluation protocols also lack standardization. One example of the diversity in methods required by evaluation protocols is the use of an ex ante, ex post or combination approach ${ }^{2}$ to the verification of energy savings. The California PUC recently ordered all utilities to switch from ex ante approaches to an ex post (and combination) framework. In New York, four utilities use an ex post based approach, while the other three use an ex ante based approach. The future trend in New York seems likely to be a switch

\footnotetext{
${ }^{2}$ Raab and Violette (1994) present the following definitions: (1) ex ante approaches generally calculate impacts by estimating the savings per DSM measure prior to installation, and then multiplying those estimates by the number of measures of each type that are actually installed. Often ex ante approaches will also have pre-specified methods for adjusting these gross impacts to net impacts such as free-rider factors. Finally, ex ante estimates are usually updated periodically with current in-field evaluation results; (2) ex post approaches generally rely on detailed process and impact evaluations subsequent to installation to determine impacts from measures and programs. Often information from engineering analyses, survey and billing data, and end-use metering are combined through statistical techniques to derive both gross and net impacts numbers. These analyses are repeated periodically to determine impacts from new participants; (3) a combination approach uses elements of both ex ante and ex post approaches.
} 
Table 3. Sources of Inconsistencies in Participation Rates

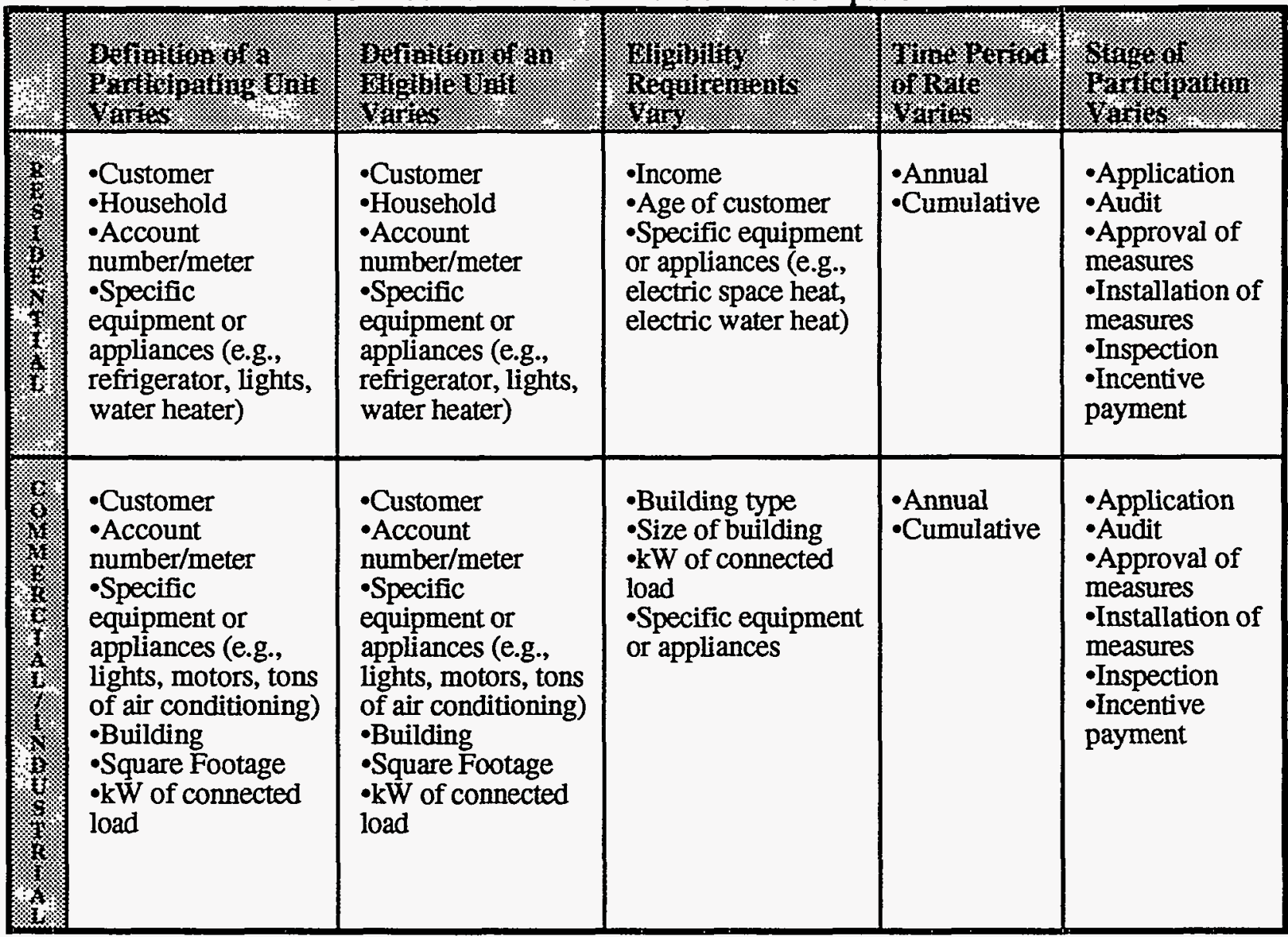

from ex post to ex ante based frameworks. In Michigan some evaluations use ex ante and some ex post approaches. Clearly, no consensus exists on which approach is preferable.

\subsection{Efforts to Promote Consistency}

In spite of the prevalence of inconsistencies, efforts to develop greater standardization continue and appear to be making slow progress. It is important to realize that any characterization of the amount of standardization is focusing on a moving target. Definitions, data reporting, and evaluation standards are continuously evolving. DSM evaluation is a multidisciplinary form of scientific research which is developing new concepts, new methods, broader knowledge and greater sophistication over time. An ongoing monitoring effort is required to stay current on the state-of-the-practice and the state-of-the-art.

\subsubsection{Current Status of Efforts to Promote Consistency. There are numerous attempts to} promote consistency which are listed in Table 4. The Northeast Regional DSM Data Exchange (NORDAX) was the first major attempt to produce a consistent set of data from many utilities on program results that could be used for program design and integrated resource planning. Currently, NORDAX has 
discontinued data collection and faces an uncertain future because its member utilities have decided to discontinue their support.

A more recent attempt to define consistent terminology and data reporting formats for utilities, commissions, and regional planners is the NU-Trak System being developed by the Northwest Power Planning Council. NU-Trak is a data collection and analysis system (that is analogous to NORDAX in its content and is based on PARADOX 4.5 for DOS) which was developed in a collaborative process with the Public Utility Commissions of Washington, Oregon, Idaho, and Montana, all six investor-owned utilities in these States, the Bonneville Power Administration, and the four largest public utilities in the region.

The purposes of NU-Trak include those of NORDAX (improving the processes of program design and integrated resource planning) plus the goal of providing useful information to state utility regulators. Jim Nybo, who is the principal developer of NU-Trak said it was a concept in April 1992. Now the first "green book" is available, which contains blank forms, full instructions for the forms, a data dictionary and glossary, and a flow chart. Still under development is a second "green book" which will have two volumes: an update of the first green book and a second volume of about 500 pages which is a data dump on over 300 programs. An evaluation module for NU-Trak also is under development. It should be ready in the fall of 1994.

At the national level, efforts to promote standard terminology and data reporting include the ORNL publication, Electric Utility DSM Programs: Terminology and Reporting Formats (Hirst and Sabo, 1991), and LBL's Database of Energy-Efficiency Programs (DEEP), which collects data that are national in scope. The objective of DEEP is to document, consistently and comprehensively, the measured cost and performance of utility-sponsored DSM programs across state jurisdictional boundaries. The developers of DEEP recognize that the consistent nationwide documentation of program results is extremely challenging because of the lack of standard definitions, reporting formats, and evaluation methods. Accordingly, DEEP is highly rigorous in several respects: consistent definitions of values, inclusion of customer cost contributions, extensive verification with utility staff, and the use of normalization procedures to ensure comparability. Although DEEP's rigorous procedures greatly reduce inconsistencies, a recently published DEEP report on 20 commercial lighting programs illustrates that consistent comparisons across programs are still often problematic (Eto, Vine, Shown, Sonnenblick, and Payne, 1994).

Although each of the standardization efforts was influenced by and built upon the earlier efforts, each also changed the earlier systems in some respects. Jim Nybo, the developer of NU-Trak, said the ORNL form was immensely helpful in developing his system. He also drew heavily from the DEEP system.

The ORNL reporting format (Hirst and Sabo, 1991) has influenced state efforts to promote standardization. For example, the California Collaborative examined the ORNL form as part of their 
deliberations and incorporated parts of it into their requirements, as did Vermont. Several other state commissions used it as input to their deliberations, but none of them adopted it without modification. Carol Sabo modified the ORNL form to fit New York Public Service Commission needs. Thus, the previously developed definitions, forms, and data reporting systems seem to be helpful to states as a starting point; but, are always adapted to unique state contexts.

Several state regulatory commissions, including California, Massachusetts, New York, and Vermont, have adopted standardized data reporting formats for their utilities. Massachusetts has the most extensive reporting format, which was first developed in 1989 (it has been revised since then, although an effort was made to keep as much consistency as possible to allow for comparisons over time). Vermont's standard data reporting requirements started in 1992. Wisconsin is in the process of developing a standard data reporting form, but nothing is adopted yet. Training sessions sponsored by EPRI include a segment on reporting formats, which focuses on the data reporting forms from Hirst and Sabo (1991), and from the Massachusetts, California, and Vermont commissions as examples.

Beginning in 1989, the Energy Information Administration has required electric utilities to provide annual reports on their DSM activities in a consistent format. This format is less detailed than the NORDAX, DEEP, or NU-Trak reporting systems.

In December 1992, ADSMP issued a compendium of glossaries of terms and definitions used in DSM evaluation. This compendium illustrates the continuing presence of inconsistencies in terminology as was discussed above. ADSMP also offers a forum for discussions of DSM issues, a variety of publications (prepared by the organization's topic committees) including a recent report on DSM evaluation standards (Peters, et al. 1994), a quarterly newsletter, and DSM evaluation training courses. The ADSMP On TRACK course on DSM evaluation contains modules on establishing a baseline and setting objectives; process, market, and impact evaluation; and, evaluation planning. It focuses on evaluation methods and covers much of the same material as the 1991 EPRI guide to impact evaluation (Violette, et al., 1991). Some attention is given to the issue of standard definitions in the course's discussion of developing a data tracking system.

3.2.2 Evaluation Protocols. Perhaps because of the 1993 California decision to adopt a detailed set of DSM evaluation protocols, concern about the issue of evaluation standards is growing. ADSMP recently issued a white paper on DSM program evaluation standards and guidelines (Peters et al., 1994). NARUC published a guide for commissioners entitled Regulating DSM Program Evaluation: Policy and Administrative Issues for Public Utility Commissions in April 1994. In most states with evaluation guidelines (of which there are currently about 15), the guidance is highly collaborative, developed on a case-by-case utility-specific basis, and does not involve a formal written protocol. 
Table 4. Efforts to Promote Consistency in Terminology, Data Reporting, and Evaluation Procedures

\begin{tabular}{|c|c|c|c|}
\hline Terninology & 9aroreporting & tranuatron Gurtance & Exraluation Rrotocols' \\
\hline NORDAX & NORDAX & & \\
\hline Hirst and Sabo & Hirst and Sabo & & \\
\hline DEEP & DEEP & & \\
\hline NU-Trak & NU-Trak & & \\
\hline \multirow[t]{2}{*}{ ADSMP glossaries } & & $\begin{array}{l}\text { ADSMP publications } \\
\text { and courses }\end{array}$ & \\
\hline & & $\begin{array}{l}\text { EPRI publications and } \\
\text { courses }\end{array}$ & \\
\hline \multirow[t]{4}{*}{$\begin{array}{l}\text { Energy Information } \\
\text { Administration }\end{array}$} & $\begin{array}{l}\text { Energy Information } \\
\text { Administration }\end{array}$ & & \\
\hline & & NARUC publications & \\
\hline & & $\begin{array}{l}\text { SRC publications and } \\
\text { courses }\end{array}$ & \\
\hline & & & $\begin{array}{l}\text { U.S. Environmental } \\
\text { Protection Agency }\end{array}$ \\
\hline California PUC & California PUC & & California PUC \\
\hline Massachusetts DPU & Massachusetts DPU & & \\
\hline New York PUC & New York PUC & & \\
\hline Vermont PSC & Vermont PSC & & \\
\hline New Jersey BRC & New Jersey BRC & & New Jersey BRC \\
\hline \multirow[t]{2}{*}{$\begin{array}{l}\text { National Association of } \\
\text { Energy Service } \\
\text { Companies }\end{array}$} & $\begin{array}{l}\text { National Association of } \\
\text { Energy Service } \\
\text { Companies }\end{array}$ & & $\begin{array}{l}\text { National Association of } \\
\text { Energy Service } \\
\text { Companies }\end{array}$ \\
\hline & & $\begin{array}{l}\text { About } 10-15 \text { state } \\
\text { regulatory commissions } \\
\text { on a case-by-case, } \\
\text { utility-specific basis }\end{array}$ & \\
\hline
\end{tabular}

a An evaluation protocol, for the purposes of this table, is defined as a formal, written document that requires specific, detailed data collection and analysis procedures for all utility DSM evaluations. Evaluation guidance, on the other hand, is more informal. It may take the form of advice, recommendations, or negotiated agreements about acceptable methods for specific situations.

Three regulatory agencies adopted evaluation protocols in 1993: the California Public Utility Commission, the New Jersey Board of Regulatory Commissioners, and the U.S. Environmental Protection Agency (EPA). The California protocol is unique in requiring estimates of end-use specific effects, which can be used in State forecasts of demand. Because California uses evaluation results in forecasting it must have consistency across utilities. All other states accept program-level estimates of effects. The protocol that New Jersey adopted deals with gross (not net) savings. It is almost exactly the same as the verification protocol developed by The National Association of Energy Service Companies in their publication, NAESCO Standard for Measurement of Energy Savings for Electric Utility Demand Side Management (DSM) Projects. The EPA Conservation Verification Protocols (CVP) were developed as part of the implementation of the Acid Rain Program of the Clean Air Act Amendments of 1990, 
which created a new tradable commodity, the $\mathrm{SO}_{2}$ emission allowance. The verification of energyefficiency savings from DSM programs is essential to this market approach. The CVP will probably be used mainly by public utilities, because investor owned utilities may verify savings with procedures specified by their regulatory commissions.

The State of Indiana is currently engaged in a rule making which will require specific types of data reporting and benefit/cost tests. Its requirements are a "moderate approach" (less extensive than the California requirements).

\section{NEED FOR INCREASED STANDARDIZATION}

Nearly all of the respondents listed in Appendix A thought that common definitions and reporting formats, at both the national and state levels, were desirable. In contrast, opinions on the desirability of standardizing evaluation methods were nearly always negative. Only a few respondents favored standard evaluation requirements by state regulators. Most respondents seemed to agree with Marty Cummings (New York PSC), who was quoted by Raab and Violette (1994, p. 4-36) in their review of regulatory issues related to DSM evaluation: "it would be a serious mistake to stifle the development of evaluation methods by imposing rigid standards that are more appropriate for special purpose verification activities."

Marty Kushler (Michigan Public Service Commission) and Ralph Prahl (Wisconsin Public Service Commission) both reported that in their states there were informal understandings between the regulators and the utilities about what was acceptable, and that expectations were negotiated on a caseby-case basis with each utility. Kushler and Prahl both believed that this was a better approach than the adoption of one set of standard evaluation methods. Kushler observed that we are too early on the learning curve to settle on a standard approach for evaluations.

No one seemed to favor (or think it was feasible to have) national evaluation standards, except in the most general sense (i.e., use of appropriate methods as judged by peers, complete and transparent reporting of methods and results). The ADSMP survey of evaluation professionals in utilities, consulting firms, and regulatory agencies that was conducted by Jane Peters (1993) found that $56 \%$ said it was premature to develop evaluation standards and that any standards setting process would have to proceed cautiously and have sufficient breadth and flexibility.

In spite of the need for caution in promulgating evaluation standards, the lack of consistent standards does create serious problems. For example, Brown and Mihlmester (1994), who reviewed 50 impact evaluations of California utility DSM programs, concluded that more information and knowledge would have been gained if similar types of programs had been evaluated using similar methodologies and if consistent reporting formats had been employed. In their review of evaluations of residential direct assistance programs, they found a variety of methods: conditional demand analysis, billing analysis, and statistically adjusted engineering methods. As a result it was difficult to separate the effect of program 
design features from differences due to methodological inconsistencies. The implementation of the California state-wide evaluation protocols should produce more consistent measurement approaches and reporting in future evaluations and thus allow for more effective comparative analysis. At the national level, the recent DEEP report on commercial lighting programs (Eto, et al., 1994) also demonstrates the continuing difficulties with comparative analyses that result from a lack of standardization.

\section{GOVERNMENTAL AND REGULATORY ROLES IN PROMOTING STANDARDIZATION}

Several respondents mentioned the value of past DOE efforts (such as Hirst and Sabo, 1991, and DEEP) and of NARUC reports (some of them funded by DOE) in promoting increased standardization. Several also suggested that DOE should continue to support such efforts. Carol Sabo suggested that NARUC could form a committee to review various glossaries and reporting formats and define a standard example. Most thought that the main role for DOE and NARUC should be an information sharing function of keeping everyone informed about what everyone else is doing. One respondent noted that a relatively small number of states are involved in developing extensive standards, so there is no need to organize committees that involve all the states. There was a consensus that federal mandates or requirements for standard definitions, data reporting formats, and evaluation protocols were not desirable. It was generally agreed that the development of standards, at either the state or national level, should be a consensus or collaborative process. All of the state evaluation and data reporting requirements examined for this report were developed through collaboratives. 


\section{REFERENCES}

Association of Demand-Side Management Professionals, 1992, Glossaries of Terms Used in DSM Evaluation and Monitoring, Evaluation and Monitoring Committee.

Brown, Marilyn and Aspen Systems Corporation, 1994. Summary of California DSM Impact Evaluation Studies, prepared by Oak Ridge National Laboratory and Aspen Systems Corporation for California DSM Measurement Advisory Committee.

Eto, Joseph, Edward Vine, Leslie Shown, Richard Sonnenblick, and Christopher Payne, 1994. A Report from the Database on Energy Efficiency Programs (DEEP) Project: The Cost and Performance of Utility Commercial Lighting Programs, LBL-34967, Lawrence Berkeley Laboratory, Berkeley, California.

Hirst, E, and C. Sabo, 1991. Electric-Utility DSM-Programs: Terminology and Reporting Formats, ORNL/CON-337, Oak Ridge National Laboratory, Oak Ridge, Tennessee.

Peters, Jane, Susan Buller, Miriam Goldberg, Nicholas Hall, Steve Harding, Elizabeth Hicks, Kim Oswald, Carol Sabo, Vince Schueler, Ed Vine, and Dan Violette, 1994. ADSMP Topic Committee White Paper: DSM Program Evaluation Standards and Guidelines, Association of Demand-Side Management Professionals.

Raab, Jonathan and Daniel Violette, 1994. Regulating DSM Program Evaluation: Policy and Administrative Issues for Public Utility Commissions, prepared by XENERGY for the National Association of Regulatory Utility Commissioners.

Violette, D., M. Ozog, M. Keneipp, F. Stern, and P. Hanser, 1991. Impact Evaluation of Demand-Side Management Programs. Volume 1: A Guide to Current Practice, CU-7179, prepared by RCG/Hagler, Bailly, Inc. for EPRI. 


\section{APPENDIX A \\ LIST OF CONTACTS}




\section{APPENDIX A}

\section{List of Contacts}

\section{DSM Experts}

Ben Bronfman, Bronfman and Associates

Kenneth Costello, National Regulatory Research Institute

Tom Eckman, Northwest Power Planning Council

Michael Foley and Ann Thompson, NARUC

Luisa Freeman, Applied Energy Group

Marjie Gardiner, Northwest Power Planning Council

Jim Nybo, Northwest Power Planning Council

Kim Oswald, Oswald Energy Associates

Jane Peters, Barakat and Chamberlin

Jonathan Raab, Raab Associates

Carol Sabo, Barakat and Chamberlin

Jeff Schlegel, Wisconsin Energy Conservation Corporation

Terry Singer, National Association of Energy Conservation Service Companies

Barry Solomon, Environmental Protection Agency

Ed Vine, Lawrence Berkeley Laboratories

\section{Public Utility Commissions}

Bill Barretti, New Jersey Board of Regulatory Commissioners

Calvin Birge, Pennsylvania Public Utility Commission

Marty Cummings, New York Public Service Commission

Chris Davis, Minnesota Department of Public Service

Andrea Kelley, Washington Utility Commission

Marty Kushler, Michigan Public Service Commission

George McClusky, New Hampshire Public Utility Commission

Theo McGregor, Massachusetts Department of Public Utilities

Robert Pauley, Indiana Utility Regulatory Commission

Ralph Prahl, Wisconsin Public Service Commission

Don Schultz, California Public Utilities Commission

Bill Stanley, Nevada Public Service Commission

Mary Beth Tighe, Maryland Public Service Commission

Rick Weston, Vermont Public Service Board 
APPENDIX B

TELEPHONE DISCUSSION GUIDE 


\begin{abstract}
APPENDIX B
TELEPHONE DISCUSSION GUIDE

\section{STANDARDIZATION OF TERMINOLOGY, DATA REPORTING FORMATS, AND EVALUATION PROCEDURES \\ (FOR DSM MONITORING, VERIFICATION AND EVALUATION)}

Which States have standard data reporting formats and evaluation protocols?

Which organizations have training materials?

HOW MUCH STANDARDIZATION IS THERE?

(If relevant, ask about ORNL publication (Hirst and Sabo) on standard terminology and data reporting formats, NORDAX, and DEEP. Are these only used by researchers who developed them or are they used by DSM trainers, utilities, and PUC's too? How widely are they known and used? Where they considered by your PUC in putting together the State protocols?)

HOW MUCH STANDARDIZATION SHOULD THERE BE? should there be any national standardization or only at State level? What are benefits and costs of national standards?

WHAT SHOULD THE ROLE OF GOVERNMENT AND REGULATORS BE IN PROMOTING STANDARDIZATION? ( NARUC, STATE PUC'S, U.S. DOE ROLES?) What should be done to promote standard terminology and reporting formats? What are the next steps?

B-1 
APPENDIX C

LIST OF DOCUMENTS EXAMINED 


\section{APPENDIX C}

\section{LIST OF DOCUMENTS EXAMINED}

Association of Demand-Side Management Professionals, 1994, On TRACK course materials.

Association of Demand-Side Management Professionals, 1992, Glossaries of Terms Used in DSM Evaluation and Monitoring, Evaluation and Monitoring Committee.

Brown, Marilyn and Aspen Systems Corporation, 1994. Summary of California DSM Impact Evaluation Studies, prepared by Oak Ridge National Laboratory and Aspen Systems Corporation for California DSM Measurement Advisory Committee.

California Public Utilities Commission. 1993. Protocols and Procedures for the Verification of Costs, Benefits, and Shareholder Earnings From Demand-Side Management Programs, November 30. These protocols were developed by a collaborative process that included the four largest utilities in California (Pacific Gas and Electric, San Diego Gas and Electric, Southern California Édison, and Southern California Gas), the California Energy Commission, Division of Ratepayer Advocates, and the National Resources Defense Council.

California Public Utilities Commission. 1994. Demand-Side Management Reporting Requirements Manual, Fifth Edition, February.

Central Vermont Public Service Corporation 1993 Annual Report. Conservation and Load Management, February 25, 1994. This is an example of the reporting to the Vermont Public Service Board that is required of each Vermont utility.

DEEP Data Collection Instrument and Instructions for Completing the DEEP Data Collection Instrument.

Eto, Joseph, Edward Vine, Leslie Shown, Richard Sonnenblick, and Christopher Payne, 1994. A Report from the Database on Energy Efficiency Programs (DEEP) Project: The Cost and Performance of Utility Commercial Lighting Programs, LBL-34967, Lawrence Berkeley Laboratory, Berkeley, California.

Hirst, E, and J. Reed (eds.), Handbook of Evaluation of Utility DSM Programs, 1991. ORNL/CON-337, Oak Ridge National Laboratory, Oak Ridge, Tennessee.

Hirst, E, and C. Sabo, Electric-Utility DSM-Programs: Terminology and Reporting Formats, 1991. ORNL/CON-337, Oak Ridge National Laboratory, Oak Ridge, Tennessee.

Massachusetts Department of Public Utilities. 1993. Definitions for Conservation and Load Management Annual Report Tables.

Northwest Power Planning Council, 1994. The Green Book: Tracking Pacific Northwest Electric Utility Conservation Achievements, 1978-92, prepared by the Northwest Power Planning Council in Cooperation with the Northwest Electric Utility Industry and the State Utility Regulatory Commissions of Idaho, Montana, Oregon, and Washington.

Northwest Power Planning Council, 1994. NU-Track, Northwest Utility Conservation Tracking System: System Documentation, prepared by the Northwest Power Planning Council in cooperation with the Northwest Electric Utility Industry and the State Utility Regulatory Commissions of Idaho, Montana, Oregon, and Washington.

Peters, Jane, Susan Buller, Miriam Goldberg, Nicholas Hall, Steve Harding, Elizabeth Hicks, Kim Oswald, Carol Sabo, Vince Schueler, Ed Vine, and Dan Violette, 1994, ADSMP Topic Committee White Paper: DSM Program Evaluation Standards and Guidelines, Association of Demand-Side Management Professionals. 
Raab, Jonathan and Daniel Violette, Regulating DSM Program Evaluation: Policy and Administrative Issues for Public Utility Commissions, 1994. prepared by XENERGY (with funds from DOE under an ORNL subcontract) for the National Association of Regulatory Utility Commissioners (based in part on interviews with Public Utility Commission staff in 12 States: California, Iowa, Vermont, Arizona, Massachusetts, Nevada, Washington, Connecticut, Michigan, New York, Florida, Wisconsin).

Residential and Commercial Sector Options Identification Paper for the EPAct Section 1605 (b) Voluntary Reporting Program, prepared for the DOE Office of Policy, Planning, and Program Evaluation, November 1993. (This appears to be an internal use paper that identifies options for developing guidelines for the voluntary reporting of greenhouse gases. It includes reviews of several conservation verification protocols. It doesn't say who prepared it)

Schlegel, J., G. Edgar, R. Prahl, M. Kushler, and D. Narum, 1993. Evaluation of DSM Shareholder Incentive Mechanisms, prepared by Wisconsin Energy Conservation Corporation for the California Public Utilities Commission. (This report has a very interesting chapter on measurement and evaluation. The testimony of these authors influenced the outcome of the hearings on the California Collaborative evaluation requirements)

State of New Jersey. Board of Regulatory Commissioners, 1993. Measurement Protocol for Commercial, Industrial, and Residential Facilities, April.

United States Environmental Protection Agency, 1993. Conservation Verification Protocols: A Guidance Document for Electric Utilities Affected by the Acid Rain Program of the Clear Air Amendments of 1990. EPA 430/8/B-92-002.

United States Environmental Protection Agency, 1993. The User's Guide to the Conservation Verification Protocols. EPA 430-B-93-002.

Violette, D., M. Ozog, M. Keneipp, F. Stern, and P. Hanser, 1991. Impact Evaluation of Demand-Side Management Programs. Volume 1: A Guide to Current Practice. CU-7179, prepared by RCG/Hagler, Bailly, Inc. for EPRI. 
APPENDIX D

GROSS AND NET IMPACTS 


\section{APPENDIX D}

\section{Gross and Net Impacts}

Definitions of gross and net impacts from a variety of sources are listed below. In each section the source is listed first, then each term is listed in bold letters which are followed by the definitions of the term.

Hirst, E, and C. Sabo, Electric-Utility DSM-Programs: Terminology and Reporting Formats, 1991. ORNL/CON-337, Oak Ridge National Laboratory, Oak Ridge, Tennessee.

Gross effect. (sometimes called total effect) is the change in electricity use or demand experienced by a customer that participated in a utility DSM program, reported in MWh/year and MW at the time of system peaks, both winter and summer, at the customer meter.

Net effect. (sometimes called program effect) is the change in electricity use or demand for a participating customer that can be attributed to the utility DSM program, expressed in $\mathrm{MWh}$ /year and $\mathrm{MW}$.

NORDAX Standard Terms: Data Collection Instrument and Utility Profile. Northeast Region DemandSide Management Data Exchange, Inc. Arlington, Virginia. 1992.

Gross Program Incremental Effects. The changes in electricity use and/or demand directly related to a program's activities during the current year by new customers participating in the DSM program.

Gross Program Annual Effects. The changes in electricity use and/or demand directly related to a program's activities during a given year by all customers participating in the DSM program.

Gross Program Cumulative Effects. The changes in electric energy use directly related to a program's activities from the program's inception through the current year by all customers participating in the program.

Net Program Incremental Effects. The changes in electricity use and/or demand directly related to a program's activities during the current year by new customers participating in the DSM program net of free riders.

Net Program Annual Effects. The changes in electricity use and/or demand directly related to a program's activities during the given year by all customers participating in the DSM program net of free riders.

Net Program Cumulative Effects. The changes in electric energy use directly related to a program's activities from the program's inception through the current year by all customers participating in the program net of free riders.

An Energy Efficiency Blueprint for California: Report of the Statewide Collaborative Process. Appendix A. Measurement Protocols for DSM Programs Eligible for Shareholder Incentives. Glossary. California Public Utilities Commission. San Francisco, California. 1990.

Net-to-Gross Impacts. Net-to-gross impacts indicate the degree to which the program induced the desired behavior, as opposed to behavior that would have taken place without the program. This effect is also termed the "free-rider" effect, although there may be slight distinctions between "free riders" and net-to-gross impacts for some programs. 
California Public Utilities Commission. 1993. Protocols and Procedures for the Verification of Costs, Benefits, and Shareholder Earnings From Demand-Side Management Programs, November 30.

Gross Load Impact. The change in energy consumption and/or demand that results directly from program-related actions taken by participants in the DSM program, regardless of why they participated.

Net Load Impact. The total change in load that is attributable to the utility DSM program. This change in load may include [sic - this is probably an error and should say exclude], implicitly or explicitly, the effects of free drivers, free riders, state or federal energy efficiency standards, changes in the level of energy service, and natural change effects.

Net-to-Gross Ratio. A factor representing net program load impacts divided by gross program load impacts that is applied to gross program load impacts to convert them into net program load impacts. This factor is also sometimes used to convert gross measure costs to net measure costs.

The protocols contain recommended measurement techniques, reporting requirements and filing deadlines for all energy efficiency DSM programs. The requirements took effect on January 1, 1994. For major measures and end uses, ex post conditional demand or statistically adjusted engineering models must be used to estimate both gross and net load impacts. Such models must be calibrated in some way to billing or metering data collected before and after the installation of measures. The use of comparison groups is encouraged for the determination of net impacts, but not required for every program type. The determination of net-to-gross ratios may rely on estimates of free riders, free drivers, spillover and rebound effects, based on statewide measurement studies.

Violette, D., M. Ozog, M. Keneipp, F. Stern, and P. Hanser, 1991. Impact Evaluation of Demand-Side Management Programs. Volume 1: A Guide to Current Practice. CU-7179, prepared by RCG/Hagler, Bailly, Inc. for EPRI.

Gross Change. The total change in electricity use between a pre-participation and postparticipation time period, includes program and non-program related factors.

Gross Impacts. The total difference between participants' electricity consumption after the program and participants' consumption before the program due to program-related actions.

Net Impacts. The change in participants' electricity consumption which is directly attributable to the program.

Net-to-Gross Impacts. Indicates the degree of program induced behavior.

Electric Integrated Resource Planning Glossary. Wisconsin Public Service Commission, Madison Wisconsin. 1991.

Does not define the terms net and gross impacts.

Demand-side Management Program Evaluation Scoping Study. Appendix B. Glossary of Terms. Empire State Electric Energy Research Corporation and Long Island Lighting Company. New York, New York. 1990.

Gross Savings. Total energy savings resulting from implementing a demand-side program. 
Gross Impact. The effect of energy usage and/or demand that are observed after a DSM program or measure is implemented and before adjustments for effects such as free ridership, free drivers and snapback have been made.

Net Savings. Gross savings less savings from free riders.

Instructions for Completing the DEEP Data Collection Instrument.

The instructions state that adjusted (which means net) energy impacts should be entered if available. They also state that unadjusted energy figures should also be noted. Effects on energy use and on demand are to be reported as in the NORDAX definitions (see above) as incremental, annual and cumulative. Respondents are to indicate which types of adjustments were made in the estimation of program savings. The list of possible types of adjustments are as follows:

control group - a control group was used

free riders - program participants who would have adopted program recommended actions during the given year regardless of the existence of the program

free drivers - people who are not formally program participants but reduce energy use because they are aware of the energy efficiency program or because of program-induced changes in the marketplace.

weather - warmer/cooler temperatures, lower/higher humidity

daylight/daylength - shorter/longer day length

building occupancy - more/less people

building function - differences in occupancy types (e.g., change in occupancy from retail to grocery)

installation of additional equipment

repair, replacement, removal, or retrofit of existing equipment

thermostat schedule and settings - higher or lower settings, shorter or longer schedules

hours of operation - shorter or longer hours of operation

power outages and other supply disruption

industrial production - changes in type and level and changes in materials or inputs agricultural production - changes in type and level, rainfall, and depth of water table other - if none of the above categories applies, check this category and provide a brief description.

State of New Jersey. Board of Regulatory Commissioners. 1993. Measurement Protocol for Commercial, Industrial and Residential Facilities.

This protocol is based almost entirely on the National Association of Energy Service Companies publication, NAESCO Standard for Measurement of Energy Savings for Electric Utility Demand Side Management (DSM) Projects. The NAESCO standards do not require the estimation of net impacts. Gross impacts are estimated from detailed before and after measurements of consumption, by end use, which are adjusted for operating hours and time of use. Savings are calculated by subtracting the postinstallation use from the base use, again accounting for time of use. The NAESCO standards do not address residential installations. The New Jersey protocol has a short chapter on "Measurement and Verification for Whole House Weatherization Programs for Existing Residences." This chapter states that "measurement and verification shall be based on billing record analysis. Savings for a residence will be the difference between base period use, pre-retrofit, and post-retrofit use, as adjusted by the use of a control group." This implies that both gross and net savings should be reported. 
APPENDIX E

FREE RIDERS AND FREE DRIVERS 


\section{APPENDIX E}

\section{Free Riders and Free Drivers}

Definitions of free riders and free drivers from a variety of sources are listed below. In each section the source is listed first, then each term is listed in bold letters which are followed by the definitions of the term.

Hirst, E, and C. Sabo, Electric-Utility DSM-Programs: Terminology and Reporting Formats, 1991. ORNL/CON-337, Oak Ridge National Laboratory, Oak Ridge, Tennessee.

Free riders are customers who would have adopted program-recommended actions even without the program, but who participate directly in the program (e.g., they claim rebates).

Free drivers are customers who take DSM-program-recommended actions because of the program, but who do not participate directly in the program (e.g., they do not claim rebates).

NORDAX Standard Terms: Data Collection Instrument and Utility Profile. Northeast Region Demand-Side Management Data Exchange, Inc. Arlington, Virginia. 1992.

Free riders. Program participants who would have adopted program recommended actions during the given year, regardless of the existence of the program.

Free ridership effects The changes in energy and/or demand of free riders; changes that are ignored in calculating program net effects.

No definition of free drivers is given.

An Energy Efficiency Blueprint for California: Report of the Statewide Collaborative Process. Appendix A. Measurement Protocols for DSM Programs Eligible for Shareholder Incentives. Glossary. California Public Utilities Commission. San Francisco, California. 1990.

Definition of free rider is included in the definition of net-to-gross impacts: Net-to-gross impacts indicate the degree to which the program induced the desired behavior, as opposed to behavior that would have taken place without the program. This effect is also termed the "free-rider" effect, although there may be slight distinctions between "free riders" and net-to-gross impacts for some programs.

No definition of free drivers is given.

California Public Utilities Commission. 1993. Protocols and Procedures for the Verification of Costs, Benefits, and Shareholder Earnings From Demand-Side Management Programs., November 30.

Free rider. A program participant who would have implemented the program measure or practice in the absence of the program.

Free driver. A nonparticipant who adopted a particular efficiency measure or practice as a result of a utility program. See "Spillover Effects" for aggregate impacts.

Spillover effects. Reductions in energy consumption and/or demand in a utility's service area caused by the presence of the DSM program, beyond the program-related gross savings of the participants. These effects could result from (a) additional energy efficiency actions that program participants take outside the program as a result of having participated; (b) changes in the array of energy-using equipment that manufacturers, dealers, and contractors offer all customers as a result of program availability; and (c) changes in the energy use of nonparticipants as a result of utility programs, whether 
direct (e.g., utility program advertising) or indirect (e.g. stocking practices such as (b) above, or changes in consumer buying habits).

Violette, D., M. Ozog, M. Keneipp, F. Stern, and P. Hanser, 1991. Impact Evaluation of Demand-Side Management Programs. Volume 1: A Guide to Current Practice. CU-7179, prepared by RCG/Hagler, Bailly, Inc. for EPRI.

Free Riders. Those individuals who would have undertaken the conservation actions promoted by the program, even if there were no program.

Free Driver Savings. The decrease in energy consumption from customers who do not participate in the program, but where the utility's DSM efforts can be viewed as causing the savings.

Moving the Market. When the behavior of an entire customer segment, both program participants and nonparticipants, is influenced by a utility's DSM program resulting in improved energy efficiency for the entire sector.

Electric Integrated Resource Planning Glossary. Wisconsin Public Service Commission, Madison Wisconsin. 1991.

Free Rider (also known as windfall). A customer who receives a utility financial incentive for conservation action which he/she would have performed even without the incentive.

No definition of free drivers is given.

Demand-side Management Program Evaluation Scoping Study. Appendix B. Glossary of Terms. Empire State Electric Energy Research Corporation and Long Island Lighting Company. New York, New York. 1990.

Freeridership. The phenomenon of customers participating in programs and obtaining incentives for actions they would do without the incentive. Such impacts are netted out in DSM program cost-effectiveness evaluations.

Freeridership Factor (FRF). FRF is the measure of the fraction of non-freeriders relative to the total number of program participants. the FRF is multiplied by the total energy/demand reductions to proportionally reduce the gross savings.

Free Drivers. Customers who install the DSM measures as a result of a DSM program do not get counted as participants because they do not apply for the program rebates.

Instructions for Completing the DEEP Data Collection Instrument.

free riders - program participants who would have adopted program recommended actions during the given year regardless of the existence of the program.

free drivers - people who are not formally program participants but reduce energy use because they are aware of the energy efficiency program or because of program-induced changes in the marketplace. 
APPENDIX F

DSM PROGRAM COSTS 


\section{APPENDIX F}

\section{DSM Program Costs}

Definitions of types of DSM program costs from a variety of sources are listed below. In each section the source is listed first, and then each term is listed in bold letters which are followed by the definitions of the term.

Hirst, E, and C. Sabo, Electric-Utility DSM-Programs: Terminology and Reporting Formats, 1991. ORNLCON-337, Oak Ridge National Laboratory, Oak Ridge, Tennessee.

Administrative costs are expenses incurred by the utility for program planning, design, management, and administration. They include labor, office supplies, data processing, and other such costs. They exclude the costs of marketing, purchase of equipment for programs, incentives, and monitoring and evaluation.

Equipment cost is the price of components that the utility purchases directly for a DSM program, including the cost of DSM measures distributed free to participants.

Marketing cost includes all expenses directly associated with the preparation and implementation of the strategies designed to encourage participation in a program.

Monitoring and evaluation cost refers to expenditures associated with the collection and analysis of data used to assess program operation and effects.

Non-utility costs are those expenses incurred by customers and trade allies that are associated with participation in a DSM program, but that are not reimbursed by the utility.

Participant costs are those expenses associated with taking part in a DSM program paid by the customer and not reimbursed by the utility.

Total program costs are all expenses associated with a DSM program regardless of whether borne by the utility, participating customer, or trade allies. The costs paid by customers and trade allies are first adjusted for incentives from the utility to avoid double-counting costs.

NORDAX Standard Terms: Data Collection Instrument and Utility Profile. Northeast Region DemandSide Management Data Exchange, Inc. Arlington, Virginia. 1992.

Direct costs. Total utility program costs.

Equipment cost (utility) The price of all equipment a utility directly purchases for a DSM program, whether for its own use or distributed free to program participants.

Implementation and delivery costs. All non-planning, non-implementation/delivery, non-incentive, non-equipment, and non-monitoring/evaluation costs incurred by the utility that are directly associated with individual customers participating in the program. Such costs include field representative, contractor time and materials, and advertising and promotional costs.

Monitoring and evaluation costs. Expenditures associated with collection and analysis of data used to assess program impacts, marketing, and processes.

Non-utility costs. All program expenses paid by customers and trade allies that are not reimbursed by the utility. 
Participant costs. All program expenses paid by customers that are not reimbursed by the utility.

Planning costs. Expenditures required for a DSM program prior to program implementation.

Total program costs. All expenses associated with a DSM program regardless of whether borne by the utility, participating customer, or trade allies. The costs paid by customers and trade allies are reduced by the value of incentives paid by the utility, if appropriate, to avoid double-counting.

Utility costs. All expenses (planning, implementation/delivery, equipment, case and non-cash incentives, monitoring and evaluation, and other) incurred by a utility in a given year for operation of a DSM program, regardless of whether the costs are capitalized or expensed.

Separate definitions of administrative and marketing costs are not included in this glossary.

An Energy Efficiency Blueprint for California: Report of the Statewide Collaborative Process. Appendix A. Measurement Protocols for DSM Programs Eligible for Shareholder Incentives. Glossary. California Public Utilities Commission. San Francisco, California. 1990.

Total costs. Total costs refers to all costs included in the Total Resource Cost test defined in the Standard Practice Manual. These costs are program costs paid by both the utility and the customer. These include all equipment costs; installation, operation and maintenance; cost of removal (less salvage value); and administrative costs. Tax credits are considered a reduction to costs.

Utility costs. Utility costs are costs incurred by the utility which are included in the Utility Cost test defined in the Standard Practice Manual. These include initial and annual costs, such as the cost of equipment, operation and maintenance, installation, program administration, and customer dropout and removal of equipment (less salvage value).

California Public Utilities Commission. 1993. Protocols and Procedures for the Verification of Costs, Benefits, and Shareholder Earnings From Demand-Side Management Programs., November 30.

Cost categories are not defined in this glossary.

Violette, D., M. Ozog, M. Keneipp, F. Stern, and P. Hanser, 1991. Impact Evaluation of Demand-Side Management Programs. Volume 1: A Guide to Current Practice. CU-7179, prepared by RCG/Hagler, Bailly, Inc. for EPRI.

Cost categories are not defined in this glossary.

Electric Integrated Resource Planning Glossary. Wisconsin Public Service Commission, Madison Wisconsin. 1991.

Cost categories are not defined in this glossary.

Demand-side Management Program Evaluation Scoping Study. Appendix B. Glossary of Terms. Empire State Electric Energy Research Corporation and Long Island Lighting Company. New York, New York. 1990.

Cost categories are not defined in this glossary. 
Instructions for Completing the DEEP Data Collection Instrument.

Annual and Cumulative Program Costs

Enter the calendar year for which the annual costs apply. Enter the start and end years for which the cumulative costs apply.

\section{Utility Costs}

Incentives. Incentives are monetary inducements in the form of a rebate or payment. Incentives costs to the utility could include reimbursement of installation and/or equipment costs as well as other costs such as cash rebates to customers and incentives to trade allies.

Administrative. Administrative costs are the costs of implementing the DSM Program. These include labor costs (such as the time of utility staff, field representatives, and contractors) as well as program support costs which are directly associated with individual customers participating in the program. Such costs include advertising and program promotion.

Measurement and Evaluation. The costs incurred for data collection and analysis to assess the performance of a DSM program. This includes the cost of equipment (such as meters) used for measurement of program energy impacts.

Total Program Costs. Total Program Costs are all utility expenses associated with a DSM program.

Planning. Costs incurred by the utility for the planning of the DSM program.

General Administration. Costs incurred by the utility for the general administration of the DSM program - for example, the cost of departmental secretaries and other administrative staff.

Shareholder Incentives. In many states, agreements with regulators allow utilities to earn bonuses or incentives for good performance in DSM. To the extent that these regulatory incentives add to the cost of the program to ratepayers, they should be reported.

Total Utility Costs. Total utility costs are all expenses incurred by a utility in a given year for operation of a DSM program, regardless of whether the costs are capitalized or expensed.

\section{Non-Utility Costs}

Participants Incremental Costs. Participants incremental costs are all program expenses paid by the customer that are net of the incentive paid by the utility.

Other Non-Utility Costs (Not Paid by Utility) Other non-utility costs include all program expenses paid by trade allies that are not reimbursed by the utility.

Total Non-Utility Costs Total non-utility costs are all program expenses paid by customers and trade allies that are not reimbursed by the utility. 
APPENDIX G

PARTICIPATION 


\section{APPENDIX G}

\section{Participation}

Definitions of types of participation from a variety of sources are listed below. In each section the source is listed first, and then each term is listed in bold letters which are followed by the definitions of the term.

Hirst, E, and C. Sabo, Electric-Utility DSM-Programs: Terminology and Reporting Formats, 1991. ORNL/CON-337, Oak Ridge National Laboratory, Oak Ridge, Tennessee.

Annual participation is the number of customers enrolled in a particular program for a given year.

Annual participation rate is the ratio of the number of participating units in a particular year to the number of eligible units.

Base market is the set of customers or technologies against which participation in a program is measured.

Cumulative participation is the number of participating units from the start of a program through the current year.

Cumulative participation rate is the ratio of the number of participating units from the start of a program through the current year to the number of eligible units.

Customer unit is a measure of participation that is based on customers, households, or buildings in contrast to technology units.

Eligible market is the subset of the total market that is qualified to participate in a program based on the program's participation criteria.

Incremental participation is the number of annual participants in the current year minus the annual participants in the previous year.

New participants are customers who take part in a program during the current year and did not participate in the program during the previous year.

Participants refers to the units used by a utility to measure participation in its DSM programs; such units of measurement include customers or households for residential programs and customers, floor area, or $\mathrm{kW}$-connected for commercial and industrial customers.

Participation rate is the ratio of the number of participants in a program to the number eligible for the program, with both the numerator and denominator defined in the same units .

NORDAX Standard Terms: Data Collection Instrument and Utility Profile. Northeast Region DemandSide Management Data Exchange, Inc. Arlington, Virginia. 1992.

Eligible customers. The number of customers in an eligible market for a given year.

Eligible market. Any set of customers or participating units that qualify for a program based on the program's eligibility requirements.

Eligibility requirements. Those criteria which a customer or unit must meet in order to participate in a DSM program.

Participants. Eligible customers who take part in a program. 
Participating units. The ultimate units used by a utility to measure program effects. Units of measure may be customers, households, facilities or firms, square feet, connected load, or equipment (and operating hours).

Participation Rate: Current Year. The ratio (expressed as a percent) of the number of new participating units to the total number of eligible units for a given year. Units may be customers. Eligible units are the units used to describe the eligible market.

Participation Rate: From Program Inception. The ratio (expressed as a percent) of the number of participating units to the total number of eligible units from program inception through the current year. Units may be customers. Eligible units are the units used to describe the eligible market.

An Energy Efficiency Blueprint for California: Report of the Statewide Collaborative Process. Appendix A. Measurement Protocols for DSM Programs Eligible for Shareholder Incentives. Glossary. California Public Utilities Commission. San Francisco, California. 1990.

Participation level. Participation level indicates the number of measures installed as part of a utility program. It encompasses measures that might have been installed in the absence of a program, as well as those installed solely as a result of the program. Depending on the nature of the measurement technique, participation may also mean the number of customers participating in the program.

California Public Utilities Commission. 1993. Protocols and Procedures for the Verification of Costs, Benefits, and Shareholder Earnings From Demand-Side Management Programs., November 30.

Participant. An individual, household, business, or other utility customer that received the service or financial assistance offered through a particular utility DSM program, set of utility programs, or particular aspect of a utility program in a given program year. Participation is determined in the same way as reported by a utility in its Annual DSM Summary.

Violette, D., M. Ozog, M. Keneipp, F. Stern, and P. Hanser, 1991. Impact Evaluation of Demand-Side Management Programs. Volume 1: A Guide to Current Practice. CU-7179, prepared by RCG/Hagler, Bailly, Inc. for EPRI.

The terms participant and participation rate are not defined in this glossary.

Program Participation Data. Utility records of rebates, equipment efficiency and capacity, and measures recommended and/or implemented by program participants.

Electric Integrated Resource Planning Glossary. Wisconsin Public Service Commission, Madison Wisconsin. 1991.

The terms participant and participation rate are not defined in this glossary.

Demand-side Management Program Evaluation Scoping Study. Appendix B. Glossary of Terms. Empire State Electric Energy Research Corporation and Long Island Lighting Company. New York, New York. 1990.

The terms participant and participation rate are not defined in this glossary. 
Instructions for Completing the DEEP Data Collection Instrument.

Data Period. Enter the calendar year, start month, and end month for which information at this stage of the program applies.

Eligibility Requirements. The eligibility requirements are those criteria which a customer or unit must meet in order to participate in a DSM program. Describe these requirements.

Describe Units used for Eligible Market. Describe the units used for defining the size of the eligible market. The units may vary between programs. In residential programs, for example, the units could be customers. In commercial programs, the units could be square feet. Other units, such as the number of lamps or ballasts, are possible.

Size of Eligible Market (in units). Enter the total size of the eligible market based on the units chosen for program eligibility. Note: If the units used to define the eligible market are customers, the total number of eligible customers will be equal to the total size of the eligible market.

Number of Customer Participants. Enter the number of eligible customers who take part in the program.

Current Year (Annual). Enter the number of customers enrolled in the program during the year specified in the Data Period above.

From Program Inception (Cumulative). Enter the number of customers enrolled from the start of the program through the year specified in the Data Period above.

Number of Participating Units. The participating units are the ultimate units used by a utility to measure program effects. Units of measure may be customers, households, facilities or firms, square feet, connected load, or equipment (and operating hours). The units chosen should be the same unit type as those used to specify the eligible market.

Current Year (Annual). Enter the total number of program participating units for the year specified in the Data Period above.

From Program Inception (Cumulative). Enter the total number of program participating units from the start of the program through the year specified in the Data Period above.

Participation Rate (\% of Eligible Customers). Enter the ratio (expressed as a percent) of the number of participating customers to the total number of eligible customers for the program. Note: If the units used to define the eligible market and participating units are customers, the Eligible Market percentage will be identical to the Eligible Customers percentage.

Participation Rate $=($ Participating Customers/Eligible Customers $) * 100$

Current Year (Annual). Enter the annual customer participation rate, i.e., the ratio $(\%)$ of the number of participating customers to the number of eligible customers in the year specified in the Data Period above.

From Program Inception (Cumulative). Enter the cumulative customer participation rate, i.e., the ration (expressed as a percent) of the number of participating customers to the number of eligible customers from the start of the program through the year specified in the Data Period above. 
Participation Rate (\% of Eligible Market). The Participation Rate is defined as the ratio (expressed as a percent) of the number of participating units in a program to the total number of eligible units for the program, with both the numerator and denominator defined in the same units. The following equation specifies the participation rate:

Participation Rate $=($ Participating Units/Eligible Units $) * 100$

Current Year (Annual). Enter the annual participation rate, i.e., the ratio (expressed as a percent) of the number of participating units to the number of eligible units for the year specified in the Data Period above.

From Program Inception (Cumulative). Enter the cumulative participation rate, i.e., the ratio (expressed as a percent) of the number of participating units to the number of eligible units from the start of the program through the year specified in the Data Period above.

Audit and Equipment Installation. For those programs offering to audit and install equipment, enter the following: (1) what percentage of customers contacted in the program agreed to be audited? and (2) of those customers that were audited, what percentage installed energy efficiency measures? 